\title{
Structure and Properties of $\mathrm{BaO}-\mathrm{B}_{2} \mathrm{O}_{3}-\mathrm{Al}_{2} \mathrm{O}_{3}-\mathrm{NaCl}$ Glass System.
}

\author{
H. A. Silim \\ Grg, Physics Department, Faculty Of Science, \\ Mansoura University, Mansoura 35516, El-Dakahlia, Egypt. \\ E-Mail:Hasilim@Hotmail.Com
}

Barium aluminoborate glass of composition: $x \mathrm{BaO}-y \mathrm{Al}_{2} \mathrm{O}_{3^{-}}(100-x-y)$ $\mathrm{B}_{2} \mathrm{O}_{3}-2 y \mathrm{NaCl}$, with $y=3$ and $x=3,8,13,18$ and $23 \mathrm{~mol} \%$ were prepared, its structure and properties were also investigated. The structure was examined using Fourier Transform Infrared (FTIR) spectroscopy. The D C electrical conductivity and glass density were also measured. The analysis of the FTIR spectra revealed that there are seven absorption peaks with three quite active ones lying in the following regions: $1200-1600 \mathrm{~cm}^{-1}, 800-1200 \mathrm{~cm}^{-1}$ and $600-800 \mathrm{~cm}^{-1}$ which are consistent with previous data reported by many authors. These peaks represent the absorption of the structure units that consists the glass matrix. The change in the position and relative area of these peaks demonstrates the structural modification accompanied with the change of the glass composition.

\section{Introduction:}

It is well known that the main structural units of the borate network which are $\left[\mathrm{BO}_{3}\right]$ triangles and $\left[\mathrm{BO}_{4}\right]^{-}$tetrahedral, may form different super structural units; boroxol and metaborate rings, metaborate chains, pentaborate, triborate, diborate and pyroborate. There are two types of $\left[\mathrm{BO}_{3}\right]$ triangles; the symmetric one with three bridging or non-bridging oxygen and the asymmetric one with one or two non-bridging oxygen [1]. Author [2] pointed out that aluminum atoms have mainly a tetrahedral coordination with respect to oxygen in barium and lead aluminoborate glasses. So it is not ruled out that the stretching vibrations of the $\mathrm{Al}-\mathrm{O}$ in $\left[\mathrm{AlO}_{4}\right]$ groups can contribute to the absorption bands in the $800-1200 \mathrm{~cm}^{-1}$. Aluminum atoms in six-fold coordination can be detected from the absorption band in $400-600 \mathrm{~cm}^{-1}$ regions In the glass system of $\mathrm{BaO}-\mathrm{Al}_{2} \mathrm{O}_{3}-\mathrm{B}_{2} \mathrm{O}_{3}$, it was reported that [3-5] $\mathrm{Al}_{2} \mathrm{O}_{3}$ behaves as $\mathrm{AlO}_{4}$ or $\mathrm{AlO}_{6}$ units in the glass structure. It was also assumed that 
aluminum ions enter the structure in the form of triclusters, where the triclusters consist of three tetrahedrals $\mathrm{BO}_{4}$ and/or $\mathrm{Al}_{2} \mathrm{O}_{3}$ in the form of $\mathrm{AlO}_{4}$ having an oxygen in common [5]. For the glass systems of $\mathrm{MO}-\mathrm{Al}_{2} \mathrm{O}_{3}-\mathrm{B}_{2} \mathrm{O}_{3} ;(\mathrm{M}=\mathrm{Sr}$, $\mathrm{Ca}$ and $\mathrm{Ba}$ ) Owen [6] proposed that some of the $\mathrm{M}$ atom associate themselves with $\mathrm{Al}_{2} \mathrm{O}_{3}$ forming $\mathrm{AlO}_{4}$ and the rest act with $\mathrm{B}_{2} \mathrm{O}_{3}$ producing $\mathrm{BO}_{4}$ or nonbridging oxygen ions. Sakka [7] concluded that the ratio $\mathrm{Al}_{2} \mathrm{O}_{3} / \mathrm{CaO}$ affects on the glass structure where $\mathrm{AlO}_{4}$ is dependent on $\mathrm{B}_{2} \mathrm{O}_{3}$ content. Pernice et.al [1] reported that the glass stability in the $\mathrm{BaO}-\mathrm{Al}_{2} \mathrm{O}_{3}-\mathrm{B}_{2} \mathrm{O}_{3}$ system increases with respect to the devitrfication process when $\mathrm{Al}$ acting as glass former.

In the present study the structure and properties of $\mathrm{BaO}-\mathrm{B} 2 \mathrm{O} 3$ glasses doped with $3 \mathrm{~mol} \%$ of $\mathrm{Al} 2 \mathrm{O} 3$ and $6 \mathrm{~mol} \%$ of $\mathrm{NaCl}$ were investigated by FTIR spectroscopy, D C electrical conductivity and density studies are carried for different compositions of these glasses.

\section{Experimental}

\subsection{Preparation of the glass samples}

The glasses under investigation having the general formula: $\mathrm{x} \mathrm{BaO}-$ $(100-\mathrm{x}-\mathrm{y}) \mathrm{B}_{2} \mathrm{O}_{3}-\mathrm{y} \mathrm{Al}_{2} \mathrm{O}_{3}-2 \mathrm{y} \mathrm{NaCl}$ with $\mathrm{y}=3$ mole $\%$ and $\mathrm{x}=3,8,13,18$ and $23 \mathrm{~mol} \%$ have been prepared using reagent-grade materials. The rawmaterials: $\mathrm{BaCO}_{3}, \mathrm{H}_{3} \mathrm{BO}_{3}, \mathrm{Al}_{2} \mathrm{O}_{3}$ and $\mathrm{NaCl}$. A mixture of these materials in appropriate portions was melted in air in porcelain crucibles in an electric furnace in the temperature range from 1100 to $1300{ }^{\circ} \mathrm{C}$ with holding time of 2.5- 3 hours depending on the glass composition. The homogenised melts were cast into stainless steel moulds and subsequently cooled down to room temperature. X-ray diffraction patterns of the prepared glasses confirmed that they are amorphous.

The compositions of the studied glasses together with its melting time and annealing temperature are given in Table (1).

\subsection{C electrical conductivity}

The D C conductivity measurements were carried out using polished samples of 1-2 mm thickness and coated with silver paste to serve as electrodes in the temperature range $270-450{ }^{\circ} \mathrm{C}$. The radius of the coated surface was of about $5 \mathrm{~mm}$. The resistance of three replicates samples (for each composition) were measured using an Insulator Tester type TM14 with $10^{3}-10^{13} \Omega$ ranges. The applied potential difference was 10 volt. The experimental error in determining the conductivity is expected to be $\approx \pm 5 \%$ whereas the estimated error in the activation energy is less than $0.11 \mathrm{eV}$.

\subsection{Density measurements}


The densities were determined out using Archimedes' method with xylene as an immersion fluid. Three replicate samples of each glass composition were used to measure the density. The random error in the density measurements was estimated to be $\pm 0.05 \%$. Density data are given in Table(1).

Table (1): Glass composition, activation energy, density. Ln $\rho_{400}$, melting time (hr) and annealing temp. $\left({ }^{\circ} \mathrm{C}\right)$.

\begin{tabular}{|l|l|l|l|l|l|l|l|l|}
\hline & $\begin{array}{l}\mathrm{BaO} \\
\mathrm{mol} \\
\%\end{array}$ & $\begin{array}{l}\mathrm{Al}_{2} \mathrm{O}_{3} \\
\mathrm{~mol} \%\end{array}$ & $\begin{array}{l}\mathrm{B}_{2} \mathrm{O}_{3} \\
\mathrm{~mol} \\
\%\end{array}$ & $\begin{array}{l}\mathrm{NaCl} \\
\mathrm{mol} \\
\%\end{array}$ & $\begin{array}{l}\text { Activatin } \\
\text { energy } \\
(\mathrm{eV})\end{array}$ & $\begin{array}{l}\text { Density } \\
\left({\mathrm{gm} . \mathrm{cm}^{-3}}^{-3}\right)\end{array}$ & $\begin{array}{l}\ln \rho_{400} \\
(\Omega . . \mathrm{cm})\end{array}$ & $\begin{array}{l}\text { melting } \\
\text { time (hr), } \\
\text { annealing } \\
\text { temp. }\left({ }^{\circ} \mathrm{C}\right)\end{array}$ \\
\hline $\mathrm{G} 10$ & 3 & 3 & 88 & 6 & 1.684 & 1.195 & 23.52 & $2.5,350$ \\
\hline $\mathrm{G} 11$ & 8 & 3 & 83 & 6 & 1.366 & 1.755 & 25.19 & $2.5,350$ \\
\hline $\mathrm{G} 12$ & 13 & 3 & 78 & 6 & 1.400 & 2.011 & 24.82 & $2.5,400$ \\
\hline $\mathrm{G} 13$ & 18 & 3 & 73 & 6 & 1.295 & 2.036 & 25.522 & $2.5,350$ \\
\hline $\mathrm{G} 14$ & 23 & 3 & 68 & 6 & 1.316 & 2.239 & 25.95 & $2.5,350$ \\
\hline
\end{tabular}

\subsection{Fourier Transformation Infrared (FTIR)}

The FTIR absorption spectra were recorded at room temperature in the range $400-4000 \mathrm{~cm}-1$ using Mattson 5000 FTIR spectrometer with a spectral resolution of $2 \mathrm{~cm}-1$. A KBr pellets technique was used where $10 \mathrm{mg}$ of each sample is mixed with $1000 \mathrm{mg}$ of $\mathrm{KBr}$ in an agate mortar. From this stock, 200 $\mathrm{mg}$ were then pressed into pellets of $13 \mathrm{~mm}$ diameter. The spectrum of each sample represents an average of 20 scans, which were normalised to the spectrum of blank $\mathrm{KBr}$ pellet; i.e. a pure $\mathrm{KBr}$ spectrum was substracted from each glass spectrum. Also, the spectra were corrected to the background and dark currents.

\section{Results and discussions:}

\subsection{Analysis of FTIR spectra}

The infrared absorption spectra of the studied glasses are shown in Fig.(1), where all the spectra are shifted upwards for the sake of clarity. In this figure $\mathrm{x}=3,8,13,18$ and $23 \mathrm{~mol} \%$ of $\mathrm{BaO}$. Fig. (2) represents an example of the deconvoluted infrared spectrum for $\mathrm{BaO}=13 \mathrm{~mol} \%$. The Gaussian shape was found to be the best fit obtained the IR bands.

The peak centre $\mathrm{C}$ and the relative area $\mathrm{R}$ of the component bands of the FTIR spectra are listed in Table (2). 


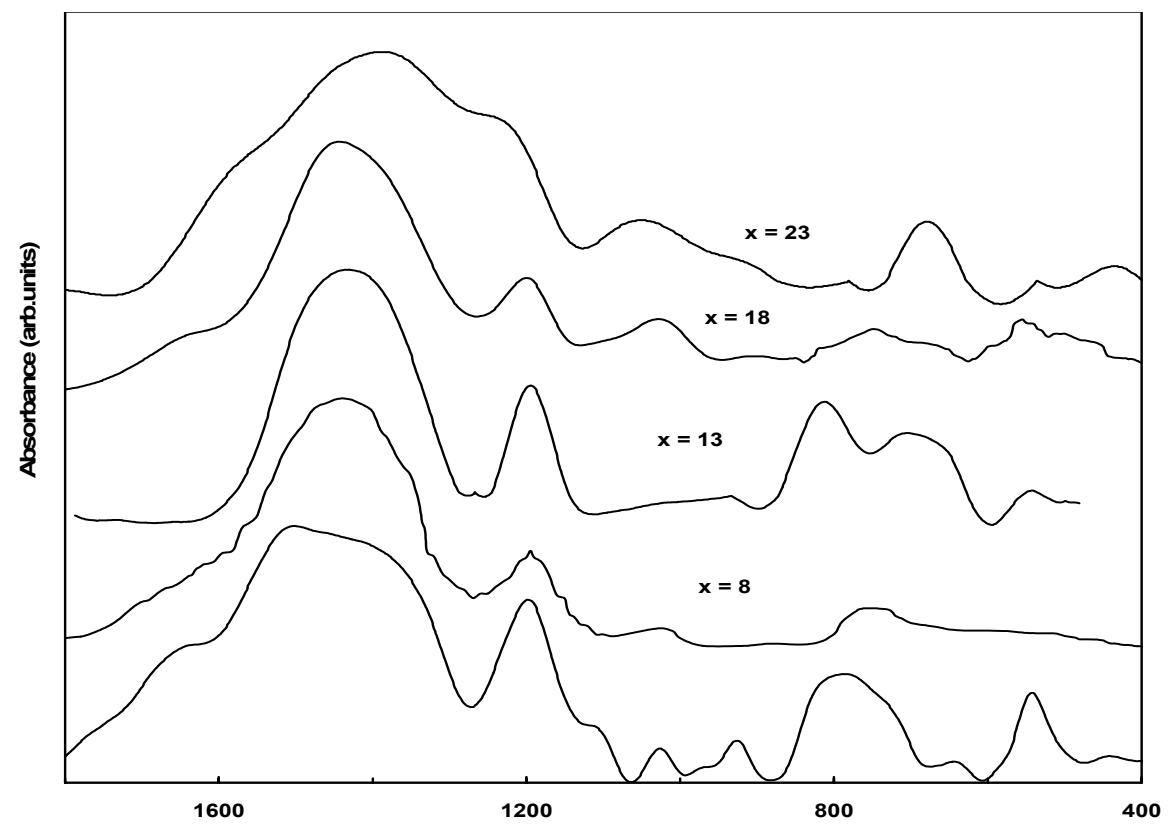

Wavenumber $\mathbf{c m}^{-1}$

Fig. (1): FTIR absorption spectra for the studied glasses with $\mathrm{x}=3,8,13,18$ and $23 \mathrm{~mol} \%$ of $\mathrm{BaO}$. Successive spectra have shifted upword.

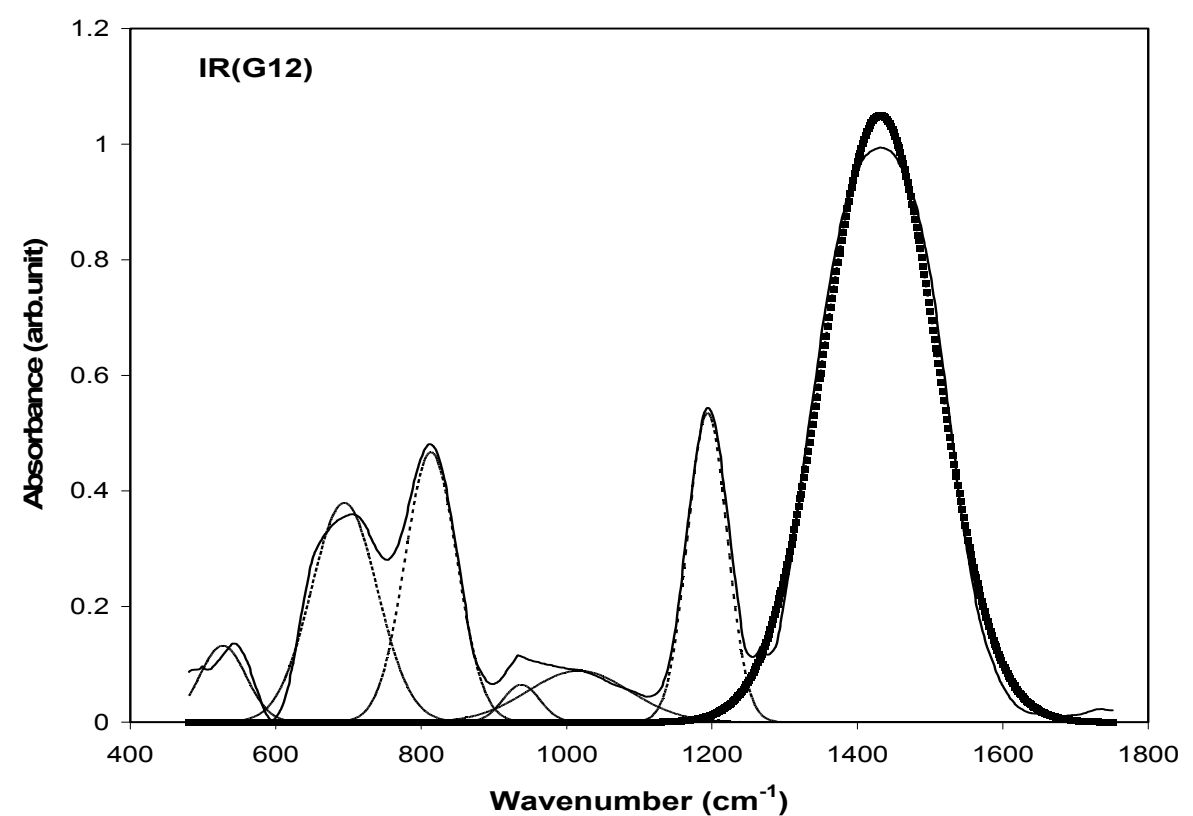

Fig. (2): Deconvolution result for $13 \mathrm{BaO}-3 \mathrm{Al}_{2} \mathrm{O}_{3}-78 \mathrm{~B}_{2} \mathrm{O}_{3}-6 \mathrm{NaCl}$, experimental absorption spectrum (solid) and computer bands (dashed lines). 
Table (2): Peak centre and relative area for the studied glasses. [C: Peak centre, $\mathrm{R}$ : Relative area]

\begin{tabular}{|c|c|c|c|c|c|c|c|c|}
\hline G10 & C & 537.5 & 777.6 & 933.1 & 1196.1 & 1360.1 & 1487.1 & 1653 \\
\hline G10 & R & 0.0451 & 0.1149 & 0.0142 & 0.1536 & 0.1713 & 0.3155 & 0.1855 \\
\hline G11 & C & 622.8 & 752.4 & 898.2 & 1047.1 & 1194.8 & 1433.4 & 1628 \\
\hline G11 & R & 0.0591 & 0.0316 & 0.0027 & 0.0313 & 0.0958 & 0.6008 & 0.1780. \\
\hline G12 & C & 527.3 & 694.4 & 813.5 & 937.7 & 1016.8 & 1193.8 & 1431.1 \\
\hline G12 & R & 0.0274 & 0.1213 & 0.1173 & 0.0114 & 0.0437 & 0.1023 & 0.5768 \\
\hline G13 & C & 494.5 & 557.7 & 747 & 1041.4 & 1201.1 & 1431 & 1662.2 \\
\hline G13 & R & 0.037 & 0.0185 & 0.0921 & 0.0942 & 0.0909 & 0.6066 & 0.0606 \\
\hline G14 & C & 433.8 & 678.5 & 963 & 1049.2 & 1218.8 & 1393.8 & 1587.1 \\
\hline G14 & R & 0.0396 & 0.0595 & 0.0995 & 0.0503 & 0.07 & 0.6718 & 0.0596 \\
\hline
\end{tabular}

According to Krogh-Moe's [8] model, the structure of the boron oxide glass consists of a random network of planer $\mathrm{BO}_{3}$ triangles with certain fraction of boroxol rings. The FTIR spectra of the studied glasses, Fig. (1), are characterised by seven absorption regions. These regions correspond to the modes of borate network are seen to be active in three infrared spectral regions which are similar to those reported on alkali borate $[8,9,10]$ and barium and aluminoborate glasses $[2,11]^{\circ}$

These regions are: (1)1200 $-1700 \mathrm{~cm}^{-1}$ is due to the asymmetric stretching of the $\mathrm{B}-\mathrm{O}$ band of triangle $\left[\mathrm{BO}_{3}\right]$ units, (2) $800-1200 \mathrm{~cm}^{-1}$ is due to the $\mathrm{B}-\mathrm{O}$ stretching vibration of tetrahedral $\left[\mathrm{BO}_{4}\right]$. units and (3) $600-800$ $\mathrm{cm}^{-1}$ due to bond bending vibration of $\mathrm{B}-\mathrm{O}-\mathrm{B}$ groups $[12,13,14]$.

In pure $\mathrm{B}_{2} \mathrm{O}_{3}$ glass, the absorption peak at $806 \mathrm{~cm}^{-1}$ wave number is a characteristic band of boroxol ring. In the present glass system the absence of this peak; except in G13; indicates the absence of boroxol ring formation, ultimately it consists of $\mathrm{BO}_{3}$ and $\mathrm{BO}_{4}$ groups The band around $1360 \mathrm{~cm}^{-1}$ in $\mathrm{G}$ 10 is assigned to $\mathrm{B}-\mathrm{O}$ stretching vibration of triagonal $\left[\mathrm{BO}_{3}\right]$ unites in metaborate, pyroborate and orthoborates [15] where the bond between $\mathrm{BO}_{3}$ and $\mathrm{BO}_{4}$ is slightly broken. The band at wave number $\leq 550 \mathrm{~cm}^{-1}$ is due to the vibration of the modifier cations $\mathrm{Na}^{+}$. The boroxol ring appears at $778 \mathrm{~cm}^{-1}$ wave number, the absorption band at $1196 \mathrm{~cm}^{-1}$ wave number are characterising of pentaborate, which consists of one $\mathrm{BO}_{4}$ and three $\mathrm{BO}_{3}$. The band at $1487 \mathrm{~cm}^{-}$ ${ }^{1}$ is assigned to the metaborate chains [10], i.e. formation of $\mathrm{BO}_{4}$ on the expense of $\mathrm{BO}_{3}$ with nonbridging oxygen [NBO]. The band at $1653 \mathrm{~cm}^{-1}$ arises from $\mathrm{B}-$ $\mathrm{O}$ stretching vibration of triangle $\left[\mathrm{BO}_{3}\right]^{-3}$ unites $[8,9,16,17]$ where the bond between $\mathrm{BO}_{4}$ and $\mathrm{BO}_{3}$ is highly broken. 
In $\mathrm{G} 11$ spectrum, the band at $623 \mathrm{~cm}^{-1}$ is assigned to the pentaborate while the bands at 752,1433 and $1628 \mathrm{~cm}^{-1}$ are similar to the bands at 778 , 1487 and $1653 \mathrm{~cm}^{-1}$ of G10, respectively. The bands around $1047 \mathrm{~cm}^{-1}$ and 1195 $\mathrm{cm}^{-1}$ could be referred to from pentaborate chains.

In $\mathrm{G} 12$, the band at $1431 \mathrm{~cm}^{-1}$ is similar to that at $1433 \mathrm{~cm}^{-1}$ of $\mathrm{G} 11$ sample, while those at $694 \mathrm{~cm}^{-1}$ and $1194 \mathrm{~cm}^{-1}$ can be assigned to the pentaborate. The absorption band at $938 \mathrm{~cm}^{-1}$ is due to the diborate network [15].

In glass sample G13, the bands at 747, 1041 and $1201 \mathrm{~cm}^{-1}$ are referred to the pentaborate, whereas those at $1431 \mathrm{~cm}^{-1}$ and $1662 \mathrm{~cm}^{-1}$ are similar to those at $1433 \mathrm{~cm}^{-1}$ in $\mathrm{G} 11$ or $1487 \mathrm{~cm}^{-1}$ and $1653 \mathrm{~cm}^{-1}$ in $\mathrm{G} 10$. The band at 558 $\mathrm{cm}^{-1}$ is assigned to the vibration of the modifier cation as in G10 sample [15].

In $\mathrm{G} 14$, the absorption peaks at $1394 \mathrm{~cm}^{-1}$ and $1587 \mathrm{~cm}^{-1}$ are similar to those at $1360 \mathrm{~cm}^{-1}$ and $1487 \mathrm{~cm}^{-1}$ of glass G10, respectively. The peaks at 679 , 1049 and $1219 \mathrm{~cm}^{-1}$ are due to the formation of pentaborate while that at 963 $\mathrm{cm}^{-1}$ is representing diborate [15].

The independence of the IR data (peak position and relative area) for the studied glass may be due to the complex modification of the glass matrix upon changing the composition. Starting with G10, it has $88 \mathrm{~mol}^{\%} \mathrm{~B}_{2} \mathrm{O}_{3}$ and the rest are $\mathrm{BaO}, \mathrm{Al}_{2} \mathrm{O}_{3}$ and $\mathrm{NaCl}$. The glass matrix will be modified with 12 mol $\%$ of three different oxides that have different rules in the glass matrix. $\mathrm{Ba}^{++}$ions will act as glass modifier and convert the $\mathrm{BO}_{3}$ triangles into $\mathrm{BO}_{4}$ groups. $\mathrm{Al}_{2} \mathrm{O}_{3}$ plays a dual rule in borate matrix as glass modifier when it added to $\mathrm{B}_{2} \mathrm{O}_{3}$ with low concentration and glass former for high concentrations. Substitution of $\mathrm{BaO}$ for $\mathrm{B}_{2} \mathrm{O}_{3}$ in the studied glass seems to leads to the conversion in the direction of the NBO's formations $[8,9,16,17]$.

This can be seen clearly from the strong overlapping of the $\mathrm{BO}_{3}$ bands in the region of $1200-1700 \mathrm{~cm}^{-1}$. The other absorption bands seem to be compositional dependence.

\subsection{C conductivity and Density}

The conductivity data showed quite agreement with Arhenius' equation:

$$
\sigma=\sigma_{\mathrm{o}} \exp (-\mathrm{E} / \mathrm{RT})
$$

Where, $\sigma_{\mathrm{o}}$ is the pre-exponential factor, $\mathrm{E}$ is the activation energy for the ionic conduction, $\mathrm{R}$ is the universal gas constant and $\mathrm{T}$ is the absolute temperature in 
$\mathrm{K}$. D C electrical conductivity for all the glass samples is measured as a function of temperature. Fig. (3) shows that the plot of $\operatorname{Ln} \rho$ versus $1000 / \mathrm{T}$ is a linear relation and the values of $\operatorname{Ln} \rho$ at any fixed temperature $\left(400^{\circ} \mathrm{C}\right)$ increases with increasing $\mathrm{BaO}$ concentration except at $8 \mathrm{~mol} \%$. The calculated activation energies from this figure are given in Table (1). A plot of activation energy versus $\mathrm{BaO}$ composition along with $\operatorname{Ln} \rho_{400}(\Omega . \mathrm{cm})$ are given in Fig.(4).

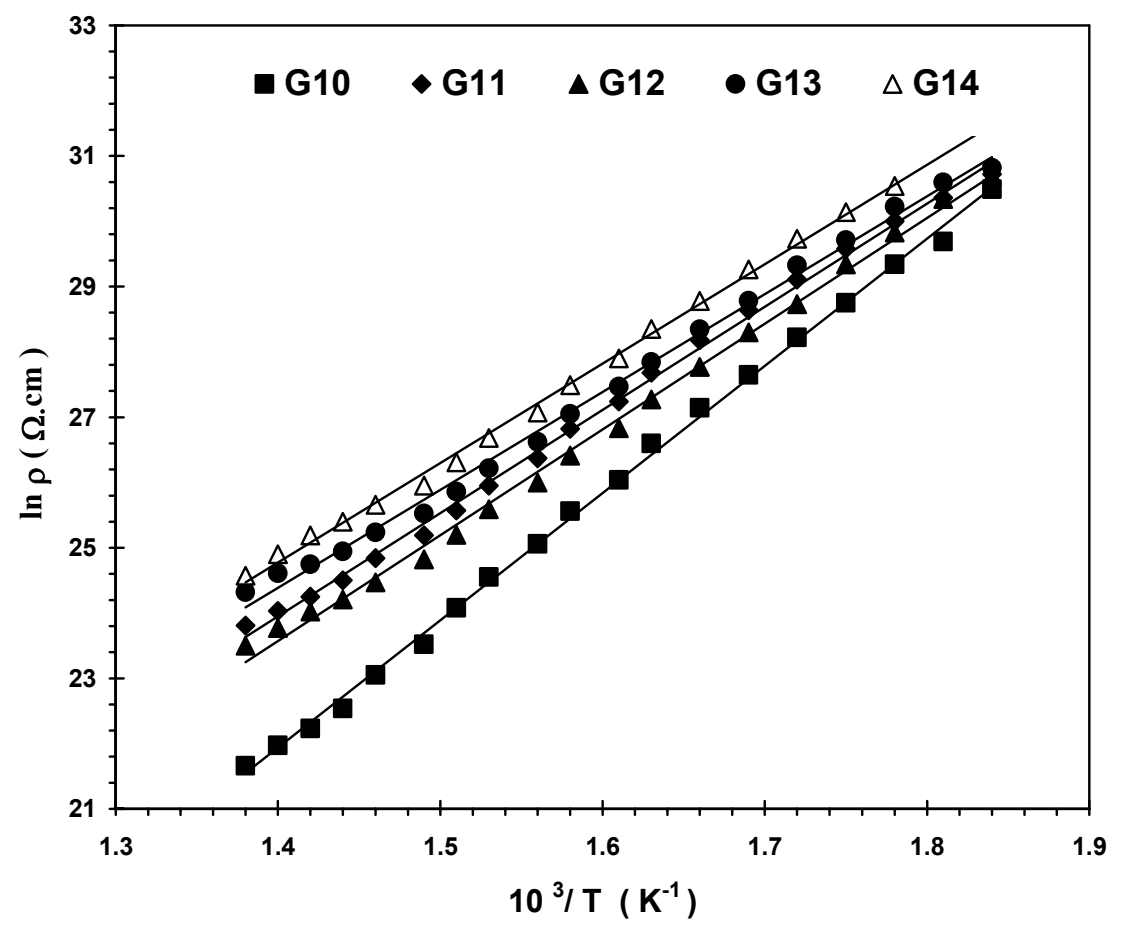

Fig. (3): Change of the natural logarithm of electric resistivity $\operatorname{Ln} \rho$ for the investigated glasses versus $1 / \mathrm{T}$.

In the glasses under investigation it is very known that $\mathrm{B}_{2} \mathrm{O}_{3}$ and $\mathrm{Al}_{2} \mathrm{O}_{3}$ in form of $\mathrm{AlO}_{4}$ are plying as glass former, $\mathrm{BaO}$ enters the network as modifier and $\mathrm{Na}^{+}$as charge carriers. Since $\mathrm{NaCl}$ is constant, thus the ratio $\mathrm{NaCl} / \mathrm{B}_{2} \mathrm{O}_{3}$ increases this means that $\mathrm{Na}^{+}$is slightly increases and an improving in the conductivity could be observed which caused the activation energies to be decreased. This means that $\mathrm{BaO}$ will act as modifier. It is known that the introducing one molecule of $\mathrm{BaO}$ into $\mathrm{B}_{2} \mathrm{O}_{3}$ converts two $\mathrm{BO}_{3}$ units into two $\mathrm{BO}_{4}$ units [18]. This leads that the mobility of the charge carries species increases with increasing transformation rate of $\mathrm{BO}_{3}$ to $\mathrm{BO}_{4}$. This process continues up to about 33 mole $\%$ of $\mathrm{BaO}$ where the number of $\mathrm{BO}_{4}$ units reaches its maximum value and $\mathrm{NBO}$ starts to be formed at $\mathrm{BaO}>33 \mathrm{~mol} \%$, 
which is inconsistent with the results of the present study, where the maximum value of $\mathrm{BaO}=23 \mathrm{~mol} \%$. This means that $\mathrm{BaO}$ is not considered as a pure charge carries as $\mathrm{Na}^{+}$but may play the role of both carriers and modifier. The formation of NBO ions leads to decreasing the height of the potential for $\mathrm{Na}$ and increasing the Ba mobility.

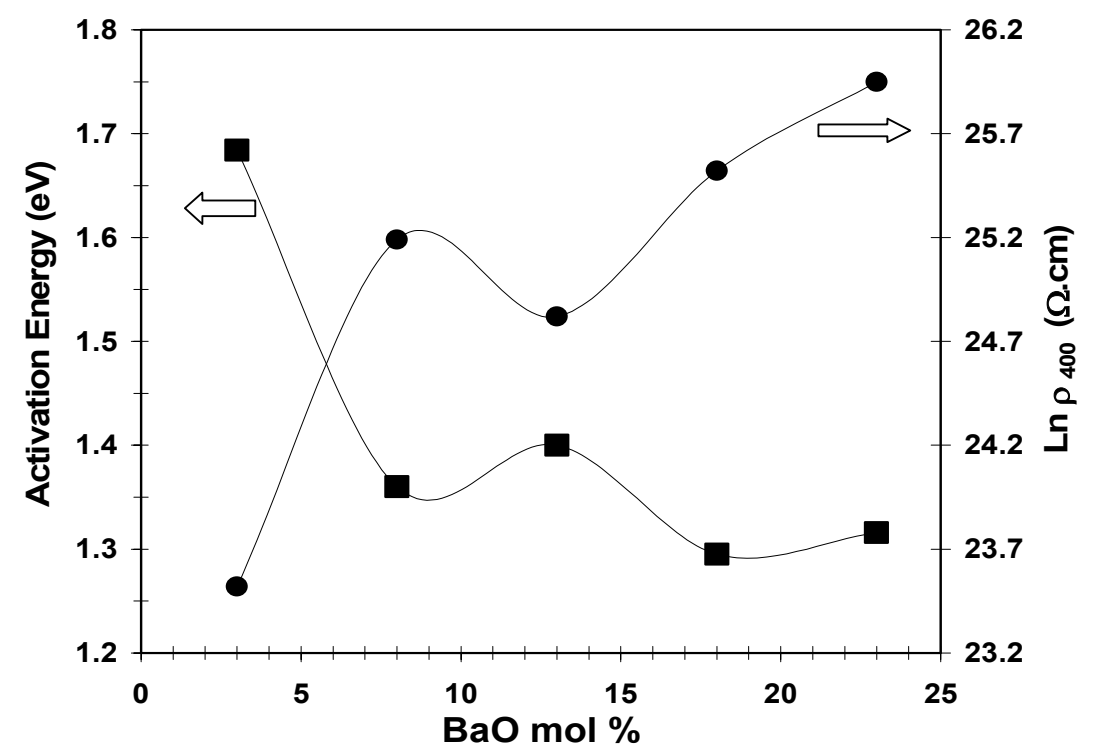

Fig. (4): Change of both the activation energy for the electrical conduction and the natural logarithm of $\mathrm{Ln} \rho$ at $400{ }^{\circ} \mathrm{C}$ versus the $\mathrm{BaO}$ content.

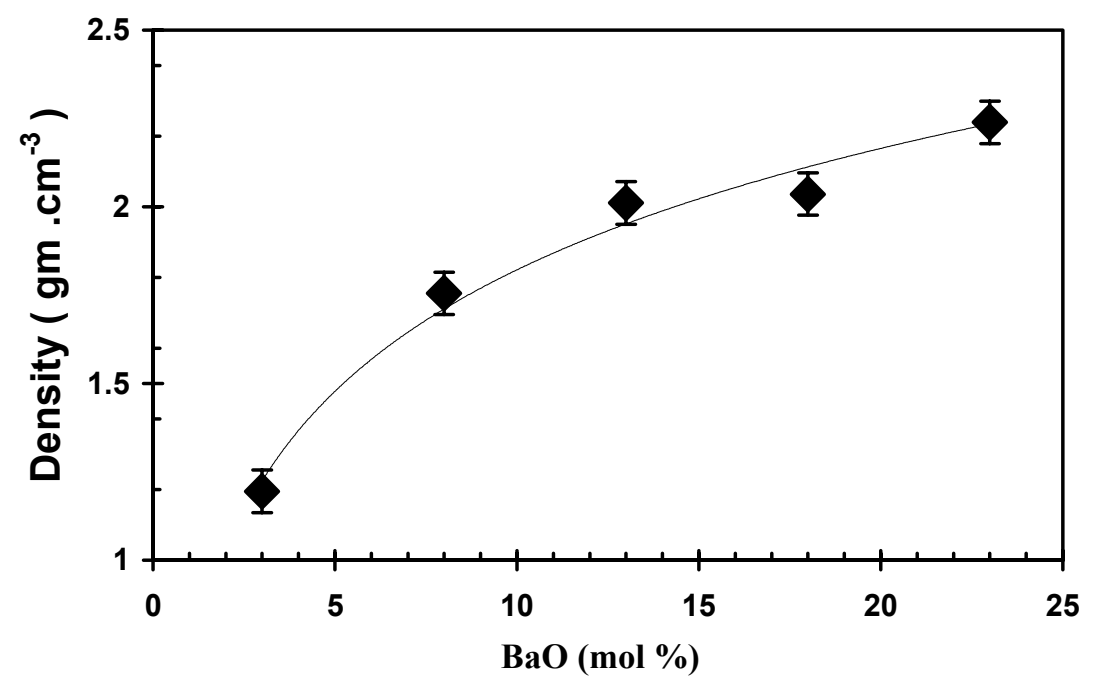

Fig. (5): Change of density with $\mathrm{BaO}$ content in the studied glasses.

Density data are given in Table (1). The relation between the density (gm / cm3) data and $\mathrm{BaO}$ content is shown in Fig. (5), where the density 
increases as $\mathrm{BaO}$ mol $\%$ is increased. This means that there are some enhancement existence of the glass as $\mathrm{B} 2 \mathrm{O} 3$ decreases.

\section{Conclusion:}

The FTIR spectroscopy for the investigated glasses showed that the Deconvoltion of effective range $(400-2000 \mathrm{~cm}-1)$ revealed that there are three active regions that are quite consistent with previous data reported by other authors. These regions are: $600-800 \mathrm{~cm}-1,800-1200 \mathrm{~cm}-1$ and $1200-1700$ $\mathrm{cm}-1$. The $\mathrm{D} \mathrm{C}$ electrical conductivity indicates that the activation energy decreases as the ratio $\mathrm{NaCl} / \mathrm{B} 2 \mathrm{O} 3$ increases and the possibility for nonbriding oxygen (NBO) to be formed is acceptable this is due to the constancy of Al2O3 and $\mathrm{NaCl}$ for all glasses. NBO ions in borate network enhance the mobility of the charge carries. The density results lead one to believe that the enhancement of glasses increases as $\mathrm{B} 2 \mathrm{O} 3$ decreasing.

\section{Acknowledgements}

I would like to thank Prof. G. El-Damrawi and Prof. Y. M. Moustafa, my colleagues in GRG, Physics Department, Mansoura University, for their useful comments, reviewing the manuscript and their assistance through out this work.

\section{References:}

1. P. Perince, S. Esposito, A. Aronne and V. N. Sigaev, J. Non-Cryst. Solids 258, 1 (1999) .

2. V. Z. Kreitsberga, V. G. Chekhovskii, A. P. Sizonenko, Yu. Ya. Keishs, S. E. Redala and P. G. Pauksh, Fiz. Khim Stekla 17, 953 (1991).

3. H.Scholze, "Glass : Nature, Structure and Properties", Springer, New York, (1991)

4. J.E. Shelby, Introduction to "Glass Science and Technology", The Royal Society of Chemistry, Combridge, (1997).

5. A.E. Owen, Phys. Chem. Glasses 2,152 (1961) .

6. Y. Naruse, A. Abe, Takami, Yogyo- Kyokai-Shi 79, 225 (1971).

7. S. Sakka, Yogyo- Kyokai-Shi 85, 299 (1977).

8. Krogh Moe, Phys. Chem. Glasses 6, 46 (1965).

9. E. I. Kamitsos, M. A. Karakassides, and G. D. Chyrssikos, Chem. Phys. Glasses 91, 1073 (1987).

10. E. I. Kamitsos, A. P. Patsis, M. A. Karakassides and G. D. Chyrssikos, J. Non-Cryst. Solids 126, 52 (1990). 
11. V. G. Chekhovskii, Yu. Ya. Keishs and Yu. A. Petrov, Fiz. Kim. Stekla 14, 150 (1988).

12. P. Perince, S. Esposits and A. Arone, Phys. Chem. Glasses 39, 222 (1998).

13. P. Perince, A. Arone and A. Marrotta, Mater. Chem. Phys. 30, 195 (1992).

14. P. Perince, A. Arone and, M. Cataura, Phys. Chem. Glasses 37, 134 (1996).

15. V. G. Chekhovskii, Fiz. Kim. Stekla 11, 24 (1985) .

16. Y. M. Moustafa, H. Doweidar and G. El-Damrawi, Phys.Chem. Glasses 35, 104 (1994).

17. E. I. Kamitsos, M. A. Karakassides and G. D. Chyrssikos, Phys. Chem. Glasses 28 (5), 203 (1987).

18. P. J. Bray, Borate Glass, Structure, Properties, Applications, ed.I. D. Pye, V. D. Frechette, N. J. Kreidle (Eds), Plenum, New York (1978). 